\title{
Linguistic and Semantic Aspects of Causation in Legal Reasoning in Modern English
}

\author{
Robert Khachatryan \\ Yerevan State Linguistic University
}

\begin{abstract}
The objective of this article is to elaborate on the significance of linguistic aspects of causation in legal reasoning in Modern English. More specifically, this article elaborates on semantic aspects of causation in legal reasoning. Linguistic aspects of causation in Modern English are instrumental in legal reasoning, particularly elaborating on the expression of the main features of lexical causatives due to their direct causation. A series of events form the causal nexus, in which the relationship is connected via spatiotemporally continuous sequences of causal intermediates. In spatiotemporal relationship of cause and effect, proximity is the criterion, which differentiates the causal connection.
\end{abstract}

Keywords: causation in legal reasoning, lexical causatives, causal nexus, proximity.

\section{Introduction}

The notion of legal language is a key feature of the broader intersection between language and legal studies. Legal language has clearly established its formal domain, in the framework of which scholars and researchers in many multidisciplinary fields investigate the empirical relationship between law and language. The history of the field in the recent three decades provides ample illustration that the explanatory force of a particular linguistic theory on legal language depends in large measure on the types of linguistic constructs it posits and the manner in which it manipulates them in order to yield wellformed linguistic representations. The task of identifying the right representations and the appropriate relations between them is quire challenging. However, it is empirically proven in practice that law is a "product of and dependent on language" (Schauer 1993), namely it is "mediated through language, partially through spoken language (e.g. at court), partially through written language (e.g. written statutory regulations, ordinances)" (Grewendorf and Rathert 2009:1). Further on, linguistic descriptions are "ubiquitous in legal disputes. Language users linguistically frame incidents from the very moment they occur and later in police reports, legal statements, court testimony, and public discourse" (Fausey and Boroditsky 2010:644). Thus, language is central to legal proceedings (Robinson 2003; Tiersma 1999) and without it there would be no way to establish legal validity (Grewendorf and Rathert 2009). In assessing the linkage between law and language, O'Barr and Conley posit, "language is the essential mechanism through which the power of law is realized, exercised, reproduced, and occasionally challenged and subverted" (O'Barr and Conley 1998:129). Most of the time, language is articulated in legal discourse, i.e. the totality of codified linguistic usages attached to legal practice among different parties: clients, lawyers, judges, disputants and witnesses, etc. Thus, law and language, each with its own unique and independent dimensions, interact on many 
levels with reciprocal influences. This intersection constitutes multidisciplinary fields, variously known as legal linguistics, forensic linguistics, legal discourse, etc. Legal professionals deploy the language and terminology of their own profession. In pursuing the aim of interpreting that language, linguists are employed to analyze and interpret the complex structure and planes of language system, as well as its particular. It is also worth mentioning that there is an "increasing sophistication of linguistics in interpreting language behavior in legal contexts as well as a greater acceptance by the law of linguistics insights as valid and helpful" (O'Barr 2001:538).

In this regard, language is systematically linked with the process of legal reasoning since understanding of the latter is central to understanding law and legal practice from a linguistic perspective. More specifically, legal reasoning incorporates the use of linguistic concepts by means of which legal phenomena or evidence can be described and explained. Setting legal phenomena into a linguistic context, legal professionals naturally search for understanding about why events happen, especially when the outcome is important or unexpected, make inferences or attributions about causes and then put all the events in chronological order. In legal reasoning, it is essential to explain legal phenomena by searching for causes and effects (consequences). Thus, legal reasoning is defined as describing, explaining, or judging legal phenomena with the use of linguistic concepts, such as causation.

\section{Causation in Legal Reasoning}

The notion of causation is an indivisible part of human cognition, where causation finds its expression on the legal and linguistic levels, incorporating special structures. The notion of causation within the domain of legal and language studies is important and challenging. It is important because ascertaining how preexisting or aggravating conditions play a role in producing causes and subsequent consequences adds to understanding the causal nexus. It is challenging because causation in legal studies and linguistics does not involve simple cause-effect relations. For example, the task of identifying the cause-effect relations in the case of linguistic evidence is generally attributed to a forensic linguist, who enhances this process by establishing the linkage between the event and its cause. More specifically, a forensic linguist can employ certain foundational principles of linguistics for evaluating the usage of the given linguistic evidence. This may be done through proving that linguistic evidence or the method is scientifically valid, through substantiating assertions made without linguistic evidence-based support or through determining the validity of a particular confession, etc. However, it should be mentioned at the outset that whenever linguistic evidence is an element of forensic expert opinion, it is not the responsibility of a forensic linguist to solely establish causation beyond a reasonable doubt. In this regard, "courts often insist that the causal questions which they have to face must be determined on common-sense principles" (Hart and Honore 1985:26) by different participants of a legal process. More specifically, the jury is tasked to determine the questions of fact, such as causation, and the judge is tasked to determine the questions of law, such as sufficient evidentiary basis (e.g. cogent evidence in the form of expert evidence), the scopes of rules, and the allocation of risks in addi- 
tion to other responsibilities.

To illustrate, some language crimes are defined in such a way that a conduct accompanied by intention to cause a harmful result may constitute the crime without regard to whether that result actually occurs. For example, it is forgery to make a false writing with intent to defraud, though no one except the author of writing sees it so that no one is actually defrauded. However, some crimes necessitate the occurrence of a certain specific result of a conduct for its commission. This may be illustrated by an example that false pretenses may probably be committed by one who recklessly makes a false statement not knowing whether the statement is true or false. Thus, emergent trends in forensic linguistics have delineated into a linguistic contention that the "importance of the linguistic reconstruction of the event turns the formulation describing it into the principal factor uniting the legal text on a syntagmatic level, on a syntactic-discursive level and on the level of the lexical structure" (Azuelos-Atias 2007:33).

Another aspect of this intersection between legal practice and language is very instrumental for the prosecution. Namely, the "prosecution's narrative must prove the existence of the causal relations mentioned in the legal definition of the offence in order to infer the criminal responsibility of the defendant" (Azuelos-Atias 2007:24). It is not enough for criminal liability that the defendant conducts himself or herself with an intention to produce the specified result, or that he or she conducts in such a manner to recklessly create a risk of that result; there exists the problem of causation. From a legalistic perspective, causation is defined as the "relationship between an act and the consequences it produces. It is one of the elements that must be proved before an accused can be convicted of a crime in which the effect of the act is part of the definition of the crime" (Martin 2003:68). Causation is further delineated into two major types: the "effective or immediate cause of the damage (causa causans) and any other cause in the sequence of events leading up to it (causa sine qua non)" (Martin 2003:69). From a linguistic standpoint, the concept of causation is defined as "some relation of determination between two events, with a prior event resulting in or giving rise to a subsequent event" (Frawley 1992:158). This phenomenon is modelled into causal chains that "consist of a series of segments, each of which relates to two participants in the event; a single participant may be involved in more than one segment" (Levin and Hovav 2005:117-18). To put it differently, a series of events forms the causal nexus, in which the relationship is connected via spatiotemporally continuous sequences of causal intermediates. Thus, the spatiotemporal continuum necessitates temporal sequence of events, i.e. a cause precedes an effect or effects in the causal nexus. The general pattern is that each event is both the effect of what happened before it and the cause of the next event, e.g. if event $a$ is a cause of event $b$, and event $b$ is a cause of event $c$, then event $a$ is a cause of event $c$. This construct has been extensively elaborated in linguistic literature. In pursuit of providing a particular constellation of certain insights and major developments in the linguistic theory of causation, several fundamentals are worth explicating. Situations that include the notion of causation are mainly comprised of "causal complex" that is a "complete set of events and conditions necessary for the causal consequent to occur" (Hobbs 2005:181). Hobbs further delineates "causal complex" as a "collection of eventualities (events or states), 
whose holding or happening entails that the effect will happen." Stemming from this theory, it may be stated that causation most often embeds events or actions, rather than states in the relationship between the cause and effect. Some event or actions not only reach a previously set aim, but also may initiate a single or series of further actions.

The causal nexus, i.e. the cause-effect relationship, rests on a fundamental premise that the effect is an event, action or state of affairs that is caused by the cause, i.e. another event/action or entity. Namely, cause is the reason behind the event, explaining why or how events happen; whereas, effect is the result of the event, i.e. the consequence of the action or the outcome of what happened. It should be mentioned that an outcome may be perceived to have internal or external causes and may vary over time. What is cause and effect is often dependent on which time horizon is chosen. Thus, it may be stated that the cause-effect relationship is multidimensional in regard to time and locus, i.e. the location of the cause.

Basically, the causal nexus factually describes an event or action that is caused by another event or action. This relationship may be presented in the following four patterns:

1. Single cause - single effect nexus, in which a single cause produces a single effect.

e.g. trigger of an explosive bullet $\rightarrow$ extensive physical damage

2. Single cause - multiple effects nexus, in which a single cause produces multiple effects.

E.g. sexual harassment by a supervisor at workplace $\rightarrow$ job termination, internal office investigation, financial liability of a supervisor

3. Multiple causes - single effect nexus, in which several causes produce a single effect.

e.g. effective collection of evidence, thorough investigation of evidence, interviewing witnesses ${ }^{\circledR}$ appropriate legal judgment of responsibility

4. Multiple causes-multiple effects nexus, in which several causes produce several effects.

E.g. a greater number of patrolling policemen on the streets, a greater number of neighborhood watch groups on the streets $\rightarrow$ decrease of crime in the neighborhood, enhanced informal social control

It is also substantial to identify the necessary causal connection between the conduct and the result of conduct. A key to establishing causation is to prove that the conduct is the "proximate cause" of the result in linguistic evidence. This includes both direct and indirect causation. Often, legal cause is the factual or direct cause of harm. Proximate cause is a flexible concept. It permits fact-finders, namely a forensic linguist, to sort through various factual causes and determine who is liable for the result. A certain result is caused under two different circumstances: (1) when a causer desires that result, whatever the likelihood of that result occurring, and (2) when a causer knows that such a result is substantially certain to occur, whatever his or her desire concerning that result. In the realm of causation, this means that (1) a causer's conduct must be a substantial factor in 
bringing about the effect, and (2) in addition the actual result cannot be brought about in a manner too different from the intended manner. Thus, in the spatiotemporal relationship of cause and effect, proximity is the criterion that differentiates the causal nexus. The function of proximity has proven difficult to identify in language. Proximity is a concept that requires the evaluation of factual states of affairs (e.g. non-linguistic settings) and linguistic evidence. Proximity mainly focuses on two components of the causal nexus - its focus being the relative positioning of the causer vis-à-vis the causee.

In the general logics of identifying proximity, it is important to discuss the expressions of "cause" and "effect" in language. The discussion will be brief and mainly based on certain illustrations in statutes. For example, the expression "cause" alone does very frequently occur in statutes although the expression "effect" is comparatively rare. Instead, a set of other causal expressions may be used both in statutory and legal language, such as "due to," "owing to," "result of," "attributable to," "lead to," "the consequence of," and "caused by." In some cases, such causal expressions may substitute the expression "effect" without alteration of meaning. Yet very often this substitution cannot be made without change of meaning or gross incongruity of expression. The "use of the term 'effect' is in fact fairly definitely confined to cases where the antecedent is literally a change or activity of some sort (as distinct from a persistent state or negative condition), and where the event spoken of as the effect is a change brought about in a person or continuing thing" (Hart and Honore 1985:27).

The above discussion is to illustrate that the majority of events are interconnected and embed the chains of actions within themselves in the causal nexus. The causal nexus is divided into three main components, every one of which denotes a different aspect of causation. These three components in the causal nexus are the causer, causative verb, and the causee.

The Causer: The causer is the instigator or the energy source of the action. There are some actions that do not require intention. When these actions are transferred into linguistic expressions, the central idea becomes the impersonal verb, i.e. the predicate and language syntax demands a subject.

\section{E.g. It rained all morning. \\ E.g. This year it will snow all winter.}

In the examples above, the central idea is the action, expressed by weather verbs. As weather verbs do not necessitate an instigator, they couple with dummy subject to form a grammatically and syntactically correct sentence. The absence of notional subject indicates the fact that there is no causation in this type of sentences. Conversely, further discussion is needed for sentences where subject is not dummy. The following examples may illustrate the point:

E.g. In this time of the year the sun rises too early.

E.g. Some men were killed by storms and accidents. 
In the first example, the action happens without any physical force used by the causer. The sun rises without any external penetration. Meanwhile, the second sentence not only embodies causative verb, but also expresses the causal nexus. The causer, i.e. storms and accidents, uses force to kill men. Therefore, the first component in the causal nexus is the causer, i.e. the instigator or the energy source of the action. It is the starting point in the process of causation, which, in the majority of cases, is also in control of the situation.

Causative verb: Causative verb is the key component in the causal nexus as it controls the flow of action. The instigator initiates the action, carried out by causative verb and further passed on to the causee, forcing it to undergo a change of state. In other words, causative verb is the intermediate link between the causer and the causee, i.e. the intention and consequence. Causative verbs generally embed actions that carry consequences and results. However, one and the same phenomenon can possess the notion of causation in one instance and be devoid of it in another.

\section{E.g. He died quietly before the sunrise. \\ E.g. Harry killed the criminal without a spark of doubt.}

As it may be inferred from the above examples, both instances indicate one and the same state - the death, but the settings are different. In the first example, the instigator dies naturally, without any force provoking it. While in the second sentence, the death occurs not naturally, but intentionally. The first verb to die is non-causative, yet the second verb to kill is causative.

Causative verbs can be of different types: verbs with semantically embedded meanings, combining both the cause and the result (lexical causatives), verbs with adjectival roots entailing verb-forming affixes to express causation (morphological causatives), and notional verbs in combination with auxiliary verbs (syntactic causatives) (Hladký and Růžička 2001:36). Thus, causative verb is the obligatory nucleus in the causal nexus and requires the causer and the causee to complete the action.

The Causee: The final component in the causative nexus is the causee, i.e. the entity that bears an effect or result of the action or undergoes a change of state. As a consequence of the action instigated by causative verb, the causee undergoes a change of state. Levin and Rappaport Hovav (2005) elaborate on the definition of the causee. The causees "are presumably arguments of an event embedded under the causing event that includes the cause and, thus, will have a less prominent realization than the cause" (Levin and Hovav 2005:169). It may be inferred that although the causee is not in control, its presence is an absolute necessity in each causative situation.

Discussing the component of the causee, it is important to distinguish two types of causation - direct and indirect. In both cases there is a possibility of a temporal or spatial gap. More specifically, an action can be originated in one case at one time and be completed at another time, i.e. a person can be wounded on the street, but die in hospital the next day. The gap is almost always existent, but its length depends on a situation (Frawley 1992:166). In the case of direct causation, maximum conceptual closeness between the causer and the causee is observed. An action contains no immediate causer, 
i.e. an action is directly instigated and implemented by the causer. There is no additional participation involved, and a temporal and spatial gap is at the minimum. The situation is different in the case of indirect causation, where the instigator and the actor are not one and the same entity. The instigator can initiate an action by giving out an order to a subordinate or initiating a special setting, but the instigator does not perform the action. In such cases, the existence of an intermediate causer is added, who, although not the instigator, is the immediate causer of an action. The spatial and temporal gap is at the maximum, thus elongating the actual relation between the causer and the causee.

\section{E.g. Bella stabbed the thief with the kitchen knife and killed him.}

Although there are no explicit hints about time or location in this example, it can be easily inferred that some time passed after the process of stabbing before the thief died. The thief could have died literally five minutes later or could have died in hospital the next day. Spatial and temporal specifics are not observable in this example as there is no context, but they are, surely possible. If the thief died from the wound of the knife, a direct causation is observed, but if the knife provoked internal bleeding, which later became the main cause of death, causation is indirect with an intermediate causer. Despite the fact that the notion of causation is delineated immediately and subconsciously in the world of actions, there are certain rules and constructions specifically designed to express causation in language.

\section{Lexical Causatives}

As any other language phenomenon, causation and its linguistic means of expression substantiate diverse nature of all languages. The concept of causation in Modern English can be expressed by three means: morphological, syntactic, and lexical. The first two categories stand for the flexibility of the English language, as auxiliary words and affixes are joined to express new meanings. Lexical causatives, on the other hand, demonstrate the richness of English lexicon, the availability of special verbs and the possibility of new creations.

Lexical causatives, known as covert and underived causatives, stand out in legal reasoning due to two features. First, they bear the meaning of causation from within since these verbs are always causative, even though they can sometimes be used in noncausative constructions. As an illustration, lexical causative verb to stab should be observed. The verb embeds the denotation of to cause to die.

E.g. Police are expected to charge a father with attempted murder after his fifteen month old son was found stabbed in his cot.

(BNC 2007: K28 75)

E.g. A few hours after the accident, Yankel Rosenbaum, 29, an Australian Hasidic Jew, was stabbed to death by a black Brooklyn gang in what appeared to be a retaliatory attack.

(BNC 2007: HLA 920) 
These two examples illustrate that the causer may differ according to the context. In the first example, the instigator is not yet known. A possible instigator, i.e. the father, is assumed to have intentionally caused his fifteen month old son to die by stabbing him. In the second example, the instigator is already proved to be a black Brooklyn gang that caused Yankel Rosenbaum to die by stabbing him to death. These two examples illustrate that the causees (a fifteen month old son and Yankel Rosenbaum) would not have died at that moment without the causers' participation (a father and a black Brooklyn gang). It is evident that the main stimulator of causation in these sentences is the causative verb to stab.

Conversely, lexical causative verb to kill with the same denotation of to cause to die can be found in sentences devoid of any causation.

E.g. From every shadowy corner in the great room appeared a growling animal, ready to kill me, it seemed.

(BNC 2007:GWH 38)

E.g. Alice went out to Monica, who was transformed by fury, ready to kill, as Alice could see.

(BNC 2007: EVI 1695)

Stemming from the contention that the structural and semantic nucleus of any sentence is the verb (Apresyan 1995; Seuren 1996), causative verb to kill is analyzed from the viewpoint of surface-syntactic and deep-semantic structures. The surface-syntactic structure signifies the form of verb, whereas the deep-semantic structure signifies the meaning of verb. Firstly, from the view of surface-syntactic structure, the verb to kill is used in infinitive to express ability and readiness, but not to instigate causation. Further on, the verb to kill is a lexical causative, and from the viewpoint of its deep-semantic structure, it preserves its causative meaning even in the examples mentioned above. As a verb with the semantically-embedded causative meaning, it necessitates a semantic causee. Secondly, lexical causatives do not embed any affix or auxiliary word. They incorporate the meanings of both cause and effect in one lexeme, hence providing maximum conceptual closeness. So, there is minimum spatial and temporal gap between the cause and effect.

Generally, the notion of causation is closely embedded with the concepts of transitivity and intransitivity of verbs. Bache states (1991:155) that verbs that do not take objects are intransitive, and those taking objects are transitive. All causative verbs are transitive as they necessitate two components in the causal nexus (Moreno 2006:79). The first component is the causer, the instigator of the action, and the other one is the causee, i.e. the entity that bears the effect or result of the action or undergoes a change of state. At the syntactic level, transitive causatives are ditransitive and necessitate both a subject (which can serve in the semantic role of the Agent) and an object (which can serve in the semantic role of the Patient or Experiencer). Further distinction between agentive (transitive) and non-agentive (intransitive) verb forms is instrumental in legal reasoning as "linguistic framing influences participants' judgments about blame and punishment... Agentive descriptions of events invite more blame and more severe punishment than do nonagentive descriptions" (Fausey and Boroditsky 2010:648-9). They explicate that a "canonical 
agentive description (e.g. Timberlake ripped the costume) includes a person as the subject in a transitive expression describing a change of state (in this case, ripping)," whereas a "canonical nonagentive description (e.g. The costume ripped) is intransitive and does not place the person as the subject for the change-of-state event" (Fausey and Boroditsky 2010:644-5). This explication is central to understanding legal reasoning in court proceedings as the transitivity-intransitivity linguistic dichotomy in law not only underlines the attributional consequences of transitivity (e.g. blame), but also the actual outcomes of these attributions (e.g. punishment).

Meanwhile, these two phenomena should not be regarded as identical. Most causative verbs are transitive and appear in transitive constructions. Transitive verbs, on the other hand, always require an object to pass the action to, but are not necessarily causative. To illustrate this contention, the following example should be analyzed.

\section{E.g. Jonathan constantly kept the ball in his hands.}

The verb to keep is transitive, but not causative. That is why a change-of-state in the object is not identified. By being kept in Jonathan's hands the ball neither changes its location nor its size. It is of utmost importance to bring forward the notion of intransitivity. Although this aspect itself does not have a direct impact on causatives, it allows the latter to expand the field of their functioning. All natural languages gradually tend to modify their own rules and eventually create new ones. As the usage of causatives expands, exceptions arise, which later find their reflection and place in the layers of language.

\section{Ergative Constructions}

It has already been mentioned that all causative verbs are transitive. However, there are many instances when intransitive verbs can express causation as well. These verbs are called ergative and contain features of both transitive and intransitive verbs. Thus, ergatives are intransitive verbs used in transitive constructions. The key factor in this case is the construction, which is transitive. These verbs are usually called ergative causatives of intransitives (Davidse and Geyskens 1998:158). Ergatives are a subtype of causative verbs and usually necessitate two animate participants. They are called differently by different scholars, namely induced action causatives (Levin 1993) or double agentive verbs (Van Valin 2001). As a rule, intransitive verbs do not take objects. Intransitive verbs are transformed into ergatives, once they take an object and denote a cause, control or energy source.

E.g. Sarah had a lot to think about, that's why she decided to walk home. E.g. It was already late, and Damian walked Sarah home.

The examples above illustrate different dimensions of the verb to walk. As can be seen in these two examples, the verb to walk which is ordinarily intransitive appears with a direct object in the active variant of the resultative. More specifically, in the first sen- 
tence the instigator of the action is Sarah, who performs the action of walking, which is internally caused. First, the verb to walk is not causative, meaning it initially cannot convey causation. Second, the verb to walk is not ordinarily transitive, meaning there is no participant to receive the effect of walking. There is only an adverbial of place, which does not undergo a change. Therefore, the verb in the first example is intransitive and non-causative. The second example contains an action generated by Damian, who is the instigator of an action directed to Sarah, the second participant undergoing a change. There are two participants and a change-of-state in the second sentence. Hence, this leads to an ergative causative. On the other hand, there is a space for debate, as there is no physical force involved in the action. Sarah herself commences the action of walking, while Damian only accompanies her. That is why these types of instances are usually considered causatives based on accompaniment (Levin 1993:18). Davidse and Geyskens (1998) suggest that these types of processes require co-participation of the participants.

Speaking about peculiarities of ergative causatives, it should also be noted that ergativeness is very similar to transitiveness, but there are a few differences. From the semantic point of view, one of differences is the alternation of deep cases or semantic roles (Agent, Patient, Goal, Instrument, Experiencer) played by noun in relation to the action. Transitive structures necessitate an instigator, the Agent (in most cases syntactically expressed by the Subject) that initiates the action and achieves a certain aim, the Goal (syntactically expressed by the object) (Halliday 1998:164). This is the most common transitive construction. Ergative constructions embed the same scheme, but their aim is the change-of-state in the Patient (syntactically expressed by the object), which can be animate and inanimate. Further on, according to Halliday (1968:185), the action is goaldirected in the case of transitivity, i.e. the action is extended beyond the syntactic object; whereas ergative constructions are based on the extent whether instigation is from outside or inside, and whether the Patient undergoes changes as a result of the action. Moreover, Davidse (1994:75) adds that the idea of cause-and-effect is especially stressed in ergative constructions.

E.g. He ate the pie completely. (The goal of the instigator is to eat the pie not to influence it)

E.g. The general marched the soldiers. (The instigator acts for the purpose of influencing the soldiers to perform a specific action)

Treating the distinctions of ergative verbs, Lakoff (1977:244) introduces a number of conditions and properties, the most significant ones of which are presented below:

1. agentivity - a human agent does something that brings about a change of state in the Patient,

2. energy source - the Agent is the source of energy for the process brought about,

3. physical manipulation - the Agent is in direct physical contact with the Patient,

4. control - the Agent controls process which the Patient undergoes,

5. intention - the Agent initiates the process deliberately,

6. patient - an (in-)animate Patient undergoes change of state. 
7. single event - the agent's action and the patient's change of state constitute a single event.

This classification can be illustrated by the example of the ergative verb to march from the prospective of Lakoff's properties.

\section{E.g. The general marched the soldiers.}

In ergative constructions, although the Agent is the instigator of the action (1), in some cases the source of the energy can be the Patient itself (Lyons 1968: 365). Even though the action takes place by the order of the general, i.e. the Agent, the energy needed for the order to be carried out is provided by the soldiers themselves, the Patient, i.e. they move their feet to march (2) (Talmy 1985:81). Furthermore, causation in this case lacks any physical force or contact (3). The action of marching is stimulated by a mental effort, namely ordering. It is important to mention that the Patient must be animate, as inanimate Patients cannot possess their own energy source and demand a physical contact from the Agent to carry out the action. Moving on to the next point, a division of control over the action should be discussed. Although the general is officially in control of the causative situation, the soldiers also have control over their bodies that act in accordance with the given order (4). The action is carried out intentionally (5). The Patient, the soldiers, change their location and position by marching, undergoing a change-of-state (6). The action, however, is not a single event, but a chain of several acts (7). Hence, it can be concluded that the example touches upon all the points of Lakoff's ergative prototype, but does not correspond to all of them. It belongs to the marginal causative type.

Such deviations are called non-direct causation (Delancey 1984:207). As Geuder and Weisgeber state, the immediate causer of an action may be one entity and the instigator - a completely different one (Geuder and Weisgeber 1999:12). In cases of external and indirect causation, the immediate causer may be a person to merely carry out a part of causation. The indirect causer, who is also the instigator, is either not involved in the actual process or retains very weak presence. Indirect causation takes place with the introduction of a new causer (whether an agent or other factors) between the direct causer and the causee. This results in the creation of several events together forming a chain of causes (Halliday 1966:38). Consider the following example.

\section{E.g. Hitler killed thousands of Jews.}

Although sometimes understood only subconsciously, Hitler is recognized as the instigator of the action, but the actual killing is attributed to other unknown officers serving at the conservation camps. However, this is not syntactically evident. Hitler did not kill the Jews himself, he only gave out the orders. Therefore, causation here is indirect because there are intermediate forces. Hitler is the indirect causer, the officers are the intermediate ones. The direct involvement of the instigator and direct causation can be illustrated by the following example. 
E.g. Officer Franz Wagner raised the gun and killed the Jew who started the rebellion in the camp.

\section{Conclusion}

As linguistic data suggests, legal reasoning incorporates the use of linguistic concepts by means of which linguistic phenomena or evidence can be described and explained. Setting legal phenomena into a linguistic context, legal professionals naturally search for understanding about why events happen, especially when the outcome is important or unexpected, make inferences or attributions about causes and then put all the events in chronological order. Linguistic aspects of causation are instrumental in legal reasoning in Modern English, particularly elaborating on the expression of the main features of lexical causatives due to their direct causation. A series of events forms the causal nexus, in which the relationship is connected via spatiotemporally continuous sequences of causal intermediates. In spatiotemporal relationship of cause and effect, proximity is the criterion which differentiates the causal nexus. All claims made in this research paper are subject to further empirical investigation since causatives constitute an undiscovered domain, which has the potential to reveal new findings about structures and usage in different contexts.

\section{References:}

1. Azuelos-Atias, S. (2007) A Pragmatic Analysis of Legal Proofs of Criminal Intent. Amsterdam: John Benjamins Publishing Company.

2. Davidse, K. (1994) Experiential Variation in the Ditransitive Paradigm. $/ 21^{\text {st }}$ International Systemic Functional Congress. Gent.

3. Davidse, K. and Geyskens, S. (1998) Have You Walked the Dog Yet? The Ergative Causativization of Intransitives. / WORD. Vol. 49 (2), pp.155-80.

4. Dixon, R.M. (2000) A Typology of Causatives: Form, Syntax and Meaning. // Changing Valency: Case Studies in Transitivity. / Ed. by Dixon R.M.W. and Aikhenvald, Al.Y. Cambridge: CUP, pp.30-83.

5. Dowty, D. (1979) Word Meaning and Montague Grammar. Dordrecht: Reidel.

6. Fausey, C.M. and Boroditsky, L. (2010) Subtle Linguistic Cues Influence Perceived Blame and Financial Liability. / Psychonomic Bulletin and Review. Vol. 17(5), pp.644650 .

7. Frawley, W. (1992) Linguistic Semantics. Hillsdale: Lawrence Erlbaum associates.

8. Geuder, W. and Weisgerber, M. (1998) Manner and Causation in Movement Verbs. Available at: <www.zas.gwz-berlin.de/papers/zaspil/articles/zp44/GeuderWeisgerber.pdf $>$ [Accessed 15.04.2014]

9. Grewendorf, G. and Rathert, M. (2009) Language and Law - New Applications of Formal Linguistics. // Formal Linguistics and Law / Ed. by Grewendorf, G. and Rathert, M. The Netherlands: Mouton de Gruyter.

10. Halliday, M.A.K. (1968) Notes on Transitivity and Theme in English. // Journal of 
Linguistics. Vol. 3. Cambridge: CUP, pp.37-81.

11. Halliday, M.A.K (1994) An Introduction to Functional Grammar. London: Edward Arnold.

12. Hart, H.L.A and Honore, T. (1985) Causation in the Law. $2^{\text {nd }}$ Ed. Oxford: At the Clarendon Press.

13. Hladký, J. and Růžička, M. (2001) A Functional Onomatology of English. Brno: Masarykova univerzita.

14. Hobbs, J.R. (2005) Toward a Useful Concept of Causality for Lexical Semantics. I Journal of Semantics. Vol. 22:181-209.

15. Lakoff, G. (1977) Linguistic Gestalts. // Papers from the $13^{\text {th }}$ Regional Meeting of the Chicago linguistic Society. / Ed. by W.A. Beach, S.E. Fox, S. Philosoph. 459-471. Chicago: Chicago University Press.

16. Leech, G. (1983) Principles of Pragmatics. London: Longman.

17. Levin, B. (1993) English Verb Classes and Alternations. Chicago: Chicago University Press.

18. Levin, B. and Hovav, M.R. (2005) Argument Realization. Cambridge: CUP.

19. Lyons, J. (1968) Introduction to Theoretical Linguistics. Cambridge, England: CUP. 20. Martin, E.A. (ed.) (2003) A Dictionary of Law. $5^{\text {th }}$ Ed. Oxford: OUP.

21. O'Barr, W.M. and Conley, J.M. (1998) Just Words: Law, Language, and Power. Chicago: Univeristy of Chicago Press.

22. O'Barr, W.M. (2001) Language, Law and Power. // The New Handbook of Language and Social Psychology. / Ed. by Robinson, W.P. and Giles, H. England: John Wiley \& Sons.

23. Robinson, M. (2003) Language and the Law. / Proceedings from a conference. Buffalo, NY: William S. Hein.

24. Schauer, F. (1993) Law and Language. NY: NY University Press

25. Seuren, P. (1996) Semantic Syntax. Oxford / Cambridge: Blackwell.

26. Shibatani, M. (ed.) (1976) The Grammar of Causative Constructions: Syntax and Semantics 6. New York: Academic Press.

27. Song, J.J. (1996) Causatives and Causation: A Universal-Typological Perspective. London and New York: Longman.

28. Talmy, L. (1985) Lexicalization Patterns: Semantic Structures in Lexical Forms. // Language Typology and Syntactic Description III: Grammatical Categories and the Lexicon. / Ed. by Shopen, T. Cambridge: CUP, pp.57-149.

29. Tiersma, P.M. (1999) Legal Language. Chicago: University of Chicago Press.

30. Van Valin, R. (2001) Lexical Representation, Co-composition, and Linking Syntax and Semantics. Available at:

$<$ http://linguistics.buffalo.edu/research/rrg/vanvalin_papers/LexRepCoCompLnkgRRG.pdf.> [Accessed April 2014] 


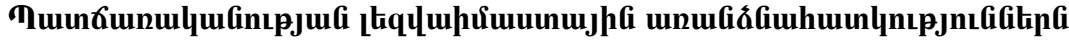

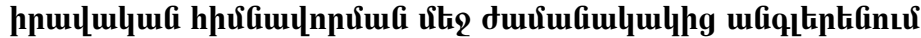

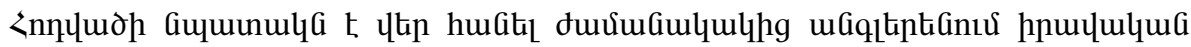

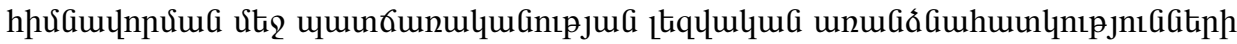

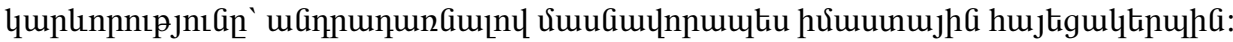

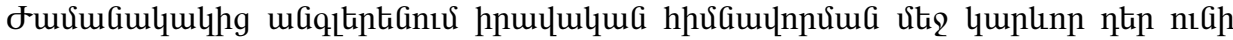

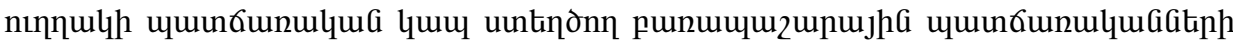

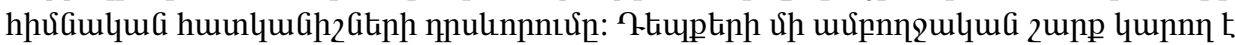

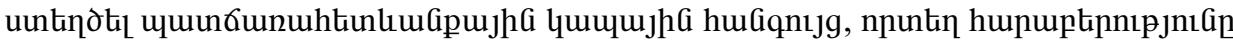

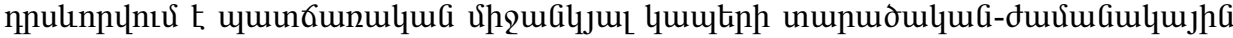

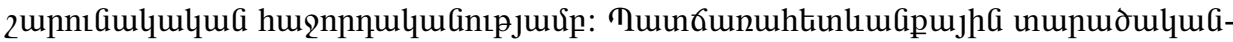

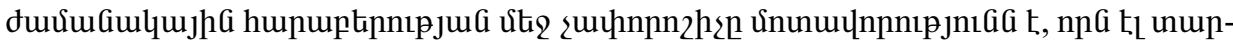

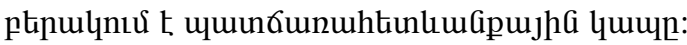

\section{Лингвистические и семантические аспекты каузативности правовом обосновании в современном английском языке}

Целью данной статьи является выявление значимости языковых аспектов каузативности в правовом обосновании в современном английском языке. В статье уделяется особое внимание семантическим аспектам. Лингвистические аспекты каузативности играют важную роль в правовом обосновании, в частности, важны разработки главных особенностей лексических каузативов, обусловленных прямыми причинно-следственными связями.

Ряд событий формирует причинную связь, в которой отношения связаны с пространственно-временной непрерывной последовательностью причинных промежуточных связей. В пространственно-временной взаимосвязи причины и следствия основным критерием, отличающим причинную связь, является приближенность. 